\title{
Chapter 12 \\ Youth Identity, Peace and Conflict: \\ Insights from Conflict and Diverse Settings
}

\author{
Shelley McKeown, Duygu Cavdar, and Laura K. Taylor
}

\subsection{Introduction}

The world is becoming increasingly ethnically diverse (Hewstone, 2015) and societies across the globe have shifted from wide-scale interstate wars to conflicts between competing groups within the same society. As a direct consequence of this changing global landscape, many of today's youth are experiencing a new social world, one which brings unique opportunities and challenges; in which young people must negotiate and develop their own sense of identity and belonging alongside historical narratives of identity.

Whilst exposure to new and different cultures can help enhance life experiences, it can also cause tensions and undermine social cohesion. Evidence for this comes from the high levels of ethnic segregation observed in spaces including schools and neighbourhoods and from across EU member states where asylum seekers, migrants and ethnic minorities are increasingly becoming targets of violence and hate speech (EU FRA, 2016). It is not surprising, therefore, that ethnic diversity and social cohesion are viewed to be at loggerheads (Putnam, 2007). Understanding how to promote better community relations amongst adolescents as the next generation of

Acknowledgements: Part of the work reported in this chapter was supported by funds from the Richard Benjamin Trust and the British Academy (BA)/Leverhulme [SG 150807]. We would like to thank the numerous school administrators, teachers and pupils for participating in this project. This work would also not have been possible without the research assistance of Jeffrey Hanna, Alexandra Kenny, Clarissa Courtney, Lauren Brown, Dean O'Driscoll, Marion Schulz, Karolina Urbanska, Lukas Horstmeier, Sofia Chirtoglou and Yangjunru (Cecilia) Li.

\author{
S. McKeown $(\triangle) \cdot$ D. Cavdar \\ University of Bristol, Bristol, UK \\ e-mail: duygu.cavdar@bristol.ac.uk \\ L. K. Taylor \\ Queen's University Belfast, Belfast, UK \\ e-mail: 1.taylor@qub.ac.uk
}


citizens is of urgent importance; but to do so, it is vital to develop a comprehensive understanding of how young people develop in such social settings and the consequences this has for community relations, both good and bad. This is because identity dynamics play a key role in societal functioning with group conflict often arising and being maintained due to competing social identities.

The aim of this chapter is to review the development of youth ethnic identity and the role of identity as a source of conflict and peace for youth growing up in conflict and diverse settings. We focus on adolescence as a critical period in which young people negotiate who they are. After outlining identity development processes, we consider ethnic identity development and how this is expressed in two case studies. First, we examine identity processes and their association with positive and negative behaviours for youth in Northern Ireland. Second, we discuss the role of identity development in light of ethnic diversity and draw on new research amongst Turkish youth in England, highlighting relevance for other contexts. We make a distinction between conflict and diverse settings as we believe that each has a unique set of circumstances that influences our understanding of adolescent identity as well as how we might best intervene to promote positive youth development. Conflict can be both violent and direct, or structural and indirect, in terms of social exclusion. When we use the word 'conflict' in this chapter, we are specifically referring to past or current political violence, whilst 'diverse' captures settings of structural violence. We conclude our chapter by outlining the possible applications of our work for policy and practice as well as highlighting suggestions for future research.

\subsection{Youth Identity Development}

We focus this chapter on adolescence as a critical time for identity development (Vega \& Gill, 2002). This is because adolescents are not only developing the cognitive abilities that allow for identity construction, but they are also faced with a wide range of choices and increased responsibility. At this time youth have accumulated experiences from across their social ecology which encourage them to actively construct who they are (Mclean \& Syed, 2015; Reidy et al., 2015; Umaña-Taylor, Quintana, \& Yip, 2014). Whilst identity development is a normative process, there are important individual, group, and cultural level differences (Motti-Stefanidi, 2015) that are vital to understand if we are to develop successful policies and interventions that serve to promote positive development for youth growing up in conflict and diverse settings. In the following section, we briefly review key theories of identity development and then consider the complexity of adolescent identity development in such settings.

Whilst a number of notable theorists have attempted to explain identity development (e.g.Berzonsky, 1990 ; Erikson, 1968 ; Marcia, 1989), perhaps the most comprehensive understanding can be attributed to Luyckx et al. (2008). In their integrative identity model, Luyckx et al. (2008) propose a process-oriented approach to identity that comprises five dimensions which are divided into exploration and 
commitment processes. Adolescents first explore in breadth with different identity alternatives, make internal investment and then explore in depth. If they remain stuck in the early stages, they enter ruminative exploration, a process that might hinder the development of and identification with commitments. Adolescents then engage in commitment processes that comprise two dimensions: commitment making (making decisions on identity-related issues) and identification with commitment (identification with and emotions after commitment).

Recognising and understanding that adolescents experience these different identity development stages has implications for when and how targeted interventions may be applied. We argue that in order to best understand adolescent identity development and later consequences, we must also consider the role of social identities. Here, we focus on ethnic identity development as relevant to conflict and diverse settings.

\subsubsection{Ethnic Identity Development}

According to social identity theory, people categorise themselves and others into in-group and out-group members; these social categorisation processes can have an impact on intergroup attitudes and behaviours (Hogg, 2016). Ethnicity is one of the major social identities we use in our daily lives (Worrell, 2015) and is a central element of self-definition (Deaux, 2001). It is hardly surprising, therefore, that ethnic identity is particularly important for youth in both conflict and diverse settings, where perceived group differences are often exaggerated. Umaña-Taylor et al. (2014) define ethnic identity as 'a multidimensional, psychological construct that reflects the beliefs and attitudes that individuals have about their ethnic-racial group memberships, as well as the processes by which these beliefs and attitudes develop over time' (p. 23). This approach to ethnic identity focuses on the content (significance and meaning of ethnicity, such as attitudes and beliefs) as well as the process (the mechanisms by which individuals explore, form and maintain their identity) of ethnic identity formation (Schwartz et al., 2014; Umaña-Taylor et al., 2014).

Ethnic identity development can be seen as an interaction between maturation and context. Adolescents gain new cognitive capacities which give them the ability to explore what ethnicity means to them (Umaña-Taylor et al., 2014). Through exploration, youth engage in culturally specific activities, behaviours and roles. And, in turn, increased autonomy and independence, social interactions, other social demands and social contexts (such as school) can affect ethnic identity development and lead to greater certainty (Steinberg, 2007; Umaña-Taylor et al., 2014). This certainty can make ethnicity more salient and when ethnicity is salient, adolescents may begin to more readily integrate experiences into their self-concept, known as identity centrality, which indicates the durable relative importance of a particular identity component or domain for an individual (Sellers, Smith, \& Chavous, 1998; Umaña-Taylor et al., 2014). Through these processes, youth develop both positive and negative feelings about their ethnic identity (Umaña-Taylor et al., 2014; 
Umaña-Taylor, Yazedjian, \& Bámaca-Gómez, 2004). Umaña-Taylor et al.'s (2004) model has been widely used and supported to explain ethnic identity formation among a range of ethnic groups (Brittian et al., 2013; Umaña-Taylor \& Shin, 2007). Through this model, it is possible to understand how the individual interacts with the social context to develop identity; this interaction is important to consider when designing policy and practice targeted to improve individual development and cross-ethnic relations.

For adolescents growing up in conflict or diverse settings, the development of ethnic identity is arguably more complicated due to a wide range of contextual factors. In such settings, youth are likely to have complex presentations of their multiple identities than individuals who live in a monocultural society (Roccas \& Brewer, 2002). Some minority youth may hold a dual identity, both the ethnocultural minority in-group and society of residence (Simon, Reichert, \& Grabow, 2013), e.g. British-Asian. Further, youth growing up in conflict settings are often exposed to the categories of 'us' and 'them' from a very young age and are taught about historical and current conflicts through family narratives that influence their identity development. Recognising this complexity, in the next section we review the literature on youth identity in conflict and diverse settings drawing on examples globally as well as focusing specifically on the contexts of Northern Ireland and England.

\subsection{Case Study 1: Youth Identity in Conflict Settings}

Youth growing up in conflict settings face several barriers in terms of positive development. There is clear evidence for the long-lasting effects of collective violence, not only among survivors (Barel, Van IJzendoorn, Sagi-Schwartz, \& BakermansKranenburg, 2010), but also for subsequent generations (Merrilees et al., 2011). Given the importance of identity development for youth, it is hardly surprising that identification is associated with a wide range of negative and positive outcomes for youth growing up in conflict settings. In such settings, understanding identity processes is particularly important because conflicts are often due to and maintained by competing social identities.

Across a wide range of conflict settings, youth social identity has been examined in relation to a host of other processes. For example, a strong sense of social identity has been found to be associated with a sense of solidarity, particularly during social change, as well as a motivating factor for engaging in such change processes, particularly among minority youth such as Palestinians in Israel (Hammack, 2010). Moreover, evidence shows that social identity can act as a protective factor for youth. In particular, a strong sense of identity buffered youth Palestinians who were exposed to violence, whilst a weaker identity among Bosnia youth left them vulnerable to such exposure (Barber, 2008). A strong sense of social identity also protected adolescents in Northern Ireland from developing greater depressive symptoms 
(Merrilees et al., 2014), but exacerbated aggression against the out-group over time (Merrilees et al., 2013). The trajectories of the strength of social identity have also been shown to vary based on group status (Merrilees et al., 2014). The development or maturation in the strength of social identity has also been found to be related to lower levels of insecurity in the community, or feeling threatened by out-group members (Merrilees et al., 2014). These studies suggest that understanding the role of social identity during adolescence is an important factor in conflict and postconflict settings. They also point to the need to consider the extent to which identities should be made salient (or not) when policies or interventions are introduced; for example, evidence above shows that identity can act as a buffer as well as a negative force on individual and societal outcomes.

Although most of the intergroup conflict research focuses on maladaptive outcomes for youth in conflict settings (e.g. prejudice; see Barber, 2009), there has been a recent shift in the literature. Adopting a risk and resilience approach, which emphasises competencies rather than only pathologies (Barber, 2013; Masten, 2014), researchers have traced a number of constructive ways, such as prosocial behaviours toward the out-group (Taylor et al., 2014) and civic engagement (Taylor et al., 2017), that young people adopt when reacting to conflict and its legacy. An example of this can be found in the research on Altruism Born of Suffering (ABS) which focuses on examining the relations among risk/harm, responses, and resources that may motivate individuals to help others (Vollhardt, 2009). ABS suggest that past experiences can lead to perceived common fate, common victim identity, perceived injustice, and increased empathy with fellow sufferers (Dovidio et al., 2010); in turn, these emotional and cognitive responses may motivate altruistic outcomes, including out-group helping (Stürmer \& Snyder, 2009; Taylor \& Hanna, 2018). Understanding the processes underlying these positive pathways following adversity, especially among young people, may be the foundation for more constructive intra- and inter-group experiences that can help to rebuild social relations. We now turn to discussing youth identity processes in Northern Ireland as a case study that can inform understanding of identity in other conflict settings.

\subsubsection{Youth Identity in Northern Ireland}

Northern Ireland as a (post) conflict society provides an opportunity to understand the role of identity for youth and its implications for peace and conflict. In this context, the historical conflict (known as the Troubles) is a still deeply entrenched ethnoreligious conflict between Protestants and Catholics. Despite the signing and implementation of 1998 Belfast/Good Friday Agreement among political elites (Cairns \& Darby, 1998), sporadic violence between Catholics and Protestants remains (MacGinty, Muldoon, \& Ferguson, 2007), and many of the communities most affected by the conflict have yet to see the dividends. Evidence for the continuing tensions between Protestants and Catholics comes from the 2016/17 hate crime 
statistics which demonstrate that of 2503 hate motivated incidents recorded, $42 \%$ were racist incidents and 40\% were sectarian incidents (PSNI, 2017).

Today, adolescents in Northern Ireland represent a 'post-accord' generation as they were born after the 1998 Peace Agreement. Although they may be socialised by their parents and communities about the impact of the Troubles (Merrilees et al., 2011), youth are also vulnerable to the lingering, though sporadic, sectarian violence which occurs across group lines. As youth develop in this context, they are negotiating multiple social identity processes which interact with such risk factors. Yet, we also argue that it is important to recognise the potential links between social identity and the peacebuilding potential of adolescents in Northern Ireland (McEvoyLevy, 2006; McKeown \& Taylor, 2017a; Taylor \& McKeown, 2017).

In terms of more positive outcomes, we found differences between Protestant and Catholic youth regarding the impact of social identity on participation in violence and civic engagement, a key factor for future peacebuilding (Taylor et al., 2017; Taylor \& McKeown, 2017). In a study of 466 youth (aged 14-15), we found that for youth with a lower strength of social identity, there was no link between group identity (Catholic or Protestant) and participation in sectarian antisocial behaviours; however, when adolescents were more committed to their social group, Protestant youth reported more participation in sectarian antisocial behaviours than Catholic youth. Similarly, there was no link between group identity and civic participation at lower levels of strength of social identity; however, among youth with stronger attachment to their social identity, Catholic youth reported more civic participation than Protestant youth (McKeown \& Taylor, 2017b). These findings suggest that the same intervention might not work equally well across groups when trying to decrease participation in sectarianism or increase constructive forms of engagement. These findings have implications for understanding the lingering effects of social identity for youth born after a peace agreement.

Given the history of the conflict, in this section we have focused on the strength of social identity related to Catholic/Protestant relations and interactions. However, amongst the post-accord generation there is greater endorsement and identification with a dual or joint Northern Irish identity (McKeown, 2014). Moreover, Northern Ireland is becoming increasingly diverse, and in response, future research should expand beyond traditional intergroup relations to understand the role of social identity with regards to other minority ethnic groups (Schulz \& Taylor, in press), particularly among adolescents. Understanding how social identity may function beyond binary distinctions is a growing area of research; we now turn to identity processes amongst ethnic minority youth.

\subsection{Case Study 2: Youth Identity in Diverse Settings}

Globally, a growing number of young people are growing up in societies with increasing ethnic diversity. Understanding how these contexts shape youth identity development has implications not only for their individual outcomes, but also for 
more peaceful and constructive societal relations. Here, we focus specifically on first- and second-generation minority youth. On the one hand, these youth may have greater opportunities than in their country of birth or that of their parents, but on the other hand, they also often face a number of challenges (e.g. stress; Umaña-Taylor \& Updegraff, 2007), disadvantages (e.g. low-income), and social difficulties (e.g. navigating a new language). For example, previous research has found a significant relationship between perceived discrimination based on ethnic identity and depression (Tummala-Narra \& Claudius, 2013; Umaña-Taylor \& Updegraff, 2007) and between mental distress and discrimination (Srivastava, 2012) for such youth. Similarly, Juang, Moffitt, and Whitborne (2016) demonstrated that discrimination is a risk factor for greater depressive symptoms, anxiety, and aggression among Latino and Asian-heritage college students in the US. Coupled with the stresses of being an ethnic minority, these experiences make youth vulnerable in terms of their mental health and wellbeing (Virupaksha, Kumar, \& Nirmala, 2014).

At the same time, a strong connection with, and positive feelings toward, an ethnic group can result in positive youth development. For example, previous research suggests that having a strong ethnic identity has a positive effect on wellbeing, such as self-esteem (Romero, Edwards, Fryberg, \& Orduña, 2014) and personal adjustment (Chae \& Foley, 2010; Phinney, 1991; Smith \& Silva, 2011). Moreover, if a young person attaches importance to their ethnic identity, feeling positively about their ethnic group is associated with better well-being (Brittian et al., 2013; Romero et al., 2014), and is predictive of less anxiety and fewer depressive symptoms among African American, Latino, and Asian American young adults in the US (Brittian et al., 2013). Thus, ethnic identity can have protective effects against mental health problems among minority youth, particularly when positive feelings are associated with that group.

Given the potential risk and protective factors associated with ethnic identity, young migrants (first, second and third generation), in particular, face a complex set of opportunities and challenges as they grow up and develop their own sense of self. Commentators argue that it can sometimes take years before individuals are able to adapt to their new socio-cultural environment (Berry, 2005) and this adaptation process may differ depending on migration status. For example, whilst first generation migrants typically experience a range of adaptation problems, such as learning a new language and settling into a new society, second generation migrants have a different challenge, negotiating two cultural worlds relating to the heritage culture of their parents/communities versus their society of birth (Berry \& Sabatier, 2010). Balancing identification with their heritage culture whilst developing an identification with the majority society is a source of stress for second generation migrant youth (Deaux, 2001). To further illustrate the arguments above, the next section draws on research findings on Turkish minority youth in England. 


\subsubsection{Turkish Youth Identity in England}

Turkish young people represent a minority group in Europe and the UK and yet, relatively little is known about identity processes of second generation youth in these contexts. Recent research has emphasised the need to understand multiple social identities, demonstrating that second generation Turkish young people struggle with identity construction, particularly in relation to culture, ethnicity, nationality and religion (Cavdar, 2017). The complexity of identity is demonstrated in Cavdar's (2017) interview ${ }^{1}$ with a young person about ethnic identity formation:

"I do not feel myself neither Turkish nor Kurdish or 100\% British as well. I grew up in a Turkish/Kurdish family. But, I am living in England and my all friends and everything in British system. But, I also love the Turkish culture; it is one of my parts." (Female, 16)

Even though youth may experience conflicted feelings during the identity construction process (Brook, Garcia, \& Fleming, 2008; Zevallos, 2008), attachment to their heritage culture can have a positive impact on their wellbeing. Specifically, engaging with activities related to their ethnic identity, attaching meaning to their ethnic identity and having positive feelings about their ethnic identity can be positively associated with adolescent wellbeing and mental health (Cavdar, 2017).

Yet, the impact of ethnic identity on second-generation Turkish youth is not always positive. There is evidence that young people report feeling under pressure to maintain the cultural traditions associated with their parents' heritage (Cavdar, 2017; Yaylaci, 2015). For example, in Cavdar's (2017) research participants reported being worried about using English as first language and losing communication with their parents, being unable to express their feelings properly in Turkish, having to translate for their parents (and this being a demanding duty), and the burden of having to code switch many times between Turkish and English. This demand on adolescents and young people can be a source of pressure or stress; they not only explore identity formation for themselves but must also help family and community members navigate life in the new society.

We argue that gaining an in-depth understanding of the contextual factors associated with adolescent ethnic identity formation and how these are experienced is vital if we are to develop programmes to promote minority youth development. For example, Umaña-Taylor, Kornienko, Bayless, and Updegraff (2018) found that making ethnic minority adolescents' ethnic-racial identity salient (i.e. exploration and resolution) promoted positive psychosocial functioning (i.e. higher global identity cohesion, higher self-esteem, lower depressive symptoms, and better grades). Further, Oyserman and Destin (2010) applied an identity-based motivation model, which assigns a central role to identity as it is dynamically constructed in context by using an integrative culturally sensitive framework in US schools, and found that

\footnotetext{
${ }^{1}$ The cited study is a part of ongoing piece of doctoral research. In this study, the author conducted an investigation on ethnic identity development of second-generation Turkish young people in the UK and how this process aligns with different acculturation strategies, perceived discrimination and mental health outcomes.
} 
the programme improved school success and reduced risk of depression. Such programmes of research, which tackle the multiplicity and complexity of ethnic identity development, offer insights for how practitioners can improve youth outcomes.

\subsection{Policy and Practice Implications}

This review offers important insights that can inform the design of policies and interventions that aim to promote positive youth development and better community relations amongst youth growing up in conflict and diverse settings. Any intervention should consider the complexity of identity development, the impact of the social context, and the positive and negative outcomes associated with social identity. Based on the work presented in this chapter, we recommend that policy makers and practitioners, including those in NGOs, working with youth, consider the need to:

1. Recognise the relevant identity development stage before designing interventions. For example, whether adolescents have already crystallised their identity shapes which approach should be taken to discuss difference or promote wellbeing.

2. Consider the potential role of group social status, such as minority, historically higher power, etc. which may lead to bespoke interventions.

3. Aim for inclusive group identification. That is, given that identification can be associated with positive outcomes, allow youth to continue to identify with the relevant social or ethnic groups. Consider multiphase programmes, which first introduce adolescents to each other as individuals, followed by discussions of group differences, and ultimately potential inclusive identities.

\subsection{Conclusion and Future Research Directions}

In this chapter, we have applied the literature on ethnic identity development to youth in conflict and diverse settings. Drawing on a range of theories, empirical evidence and two case studies, we have demonstrated both the protective and problematic impact of identity on youth attitudes and behaviours in such settings. Complementing current research which has developed comprehensive theoretical frameworks that consider the complexity of identity processes for youth, we suggest two main avenues for future research that will inform interventions aiming to promote positive youth development.

First, we urge researchers to consider positive youth development, rather than seeing youth only as either passive victims or perpetrators of harm. For example, studies should include measures on empathy, prosocial behaviours, and civic engagement, which may all be key antecedents for later peacebuilding (McKeown \& Taylor, 2017a; O’Driscoll, Taylor, \& Dautel, in press). Understanding how ethnic 
identity development is related to these positive outcomes (moving beyond mental health and also considering behaviour), and change across adolescence, will shed new light on social identity processes. Recognising constructive youth agency will enable us to understand how to harness and promote more positive youth attitudes and behaviours.

Second, researchers should consider a social ecology approach to more fully understand how youth identity develops. Youth development is influenced by the interaction among individual characteristics (e.g. personality and political ideology), the immediate social context (e.g. peers, family, school and neighbourhood norms of interaction), and factors that indirectly influence behaviour (e.g. governmental structures, cultural patterns). Such a comprehensive approach will better inform programme development at various levels, as well as shape interventions that tackle cross-cutting issues. An integrative focus that also critically engages policymakers has the potential to have multiplicative effects beyond direct participants in such programmes. Combined with an emphasis on constructive youth outcomes, such an approach has the potential to galvanise the peacebuilding potential of adolescent social identities.

\section{References}

Barber, B. K. (2008). Contrasting portraits of war: Youths' varied experiences with political violence in Bosnia and Palestine. International Journal of Behavioral Development, 32, 298-309. https://doi.org/10.1177/0165025408090972

Barber, B. K. (Ed.). (2009). Adolescents and war: How youth deal with political violence. New York, NY: Oxford University Press.

Barber, B. K. (2013). Annual research review: The experience of youth with political conflictchallenging notions of resilience and encouraging research refinement. Journal of Child Psychology and Psychiatry, 54, 461-473. https://doi.org/10.1111/jcpp.12056

Barel, E., Van IJzendoorn, M. H., Sagi-Schwartz, A., \& Bakermans-Kranenburg, M. J. (2010). Surviving the holocaust: A meta-analysis of the long-term sequelae of a genocide. Psychological Bulletin, 136, 677-698. https://doi.org/10.1037/a0020339

Berry, J. W. (2005). Acculturation: Living successfully in two cultures. International Journal of Intercultural Relations, 29, 697-712. https://doi.org/10.1016/j.ijintrel.2005.07.013

Berry, J. W., \& Sabatier, C. (2010). Acculturation, discrimination, and adaptation among second generation immigrant youth in Montreal and Paris. International Journal of Intercultural Relations, 34, 191-207. https://doi.org/10.1016/j.ijintrel.2009.11.007

Berzonsky, M. D. (1990). Self-construction over the life-span: A process perspective on identity formation. In G. J. Neimeyer \& R. A. Neimeyer (Eds.), Advances in personal construct psychology. Advances in personal construct psychology: A research annual, Vol. 1, (pp. 155-186). US: Elsevier Science/JAI Press.

Brittian, A. S., Umaña-Taylor, A. J., ... Caraway, S. J. (2013). The moderating role of centrality on associations between ethnic identity affirmation and ethnic minority college Students' mental health. Journal of American College Health, 61, 133-140. https://doi.org/10.1080/07448481. 2013.773904

Brook, A. T., Garcia, J., \& Fleming, M. (2008). The effects of multiple identities on psychological well-being. Society for Personality and Social Psychology, 34, 1588-1600. https://doi. org/10.1177/0146167208324629 
Cairns, E., \& Darby, J. (1998). The conflict in Northern Ireland: Causes, consequences, and controls. American Psychologist, 53, 754-760. https://doi.org/10.1037/0003-066X.53.7.754

Cavdar, D. (2017). Identity formation in adolescence: Mental health, acculturation, and discrimination among young immigrants in the UK (a pilot study). Bristol: School of Education, University of Bristol. Unpublished doctoral progression document.

Chae, M. H., \& Foley, P. F. (2010). Relationship of ethnic identity, acculturation, and psychological well-being among Chinese, Japanese, and Korean Americans. Journal of Counseling \& Development, 88, 466-476. https://doi.org/10.1002/j.1556-6678.2010.tb00047.x

Deaux, K. (2001). Social identity. In J. Worrell (Ed.), Encyclopaedia of women and gender (pp. 1059-1067). San Diego, CA: Academic Press.

Dovidio, J. F., Johnson, J. D., Gaertner, S. L., Pearson, A. R., Saguy, T., \& Ashburn-Nardo, L. (2010). Empathy and intergroup relations. In M. Mikulincer \& P. Shaver (Eds.), Prosocial Motives, Emotion, and Behavior: The Better Angels of our Nature (pp. 393-408). Washington, DC: APA Press.

Erikson, E. H. (1968). Identity: Youth and crisis. New York: W.W. Norton \& Company, Inc.

European Union Agency for Fundamental Rights [EU FRA]. (2016). Current migration situation in the EU: Hate crime. Retrieved from: http://fra.europa.eu/en/publication/2016/ current-migration-situation-eu-hate-crime

Hammack, P. L. (2010). Identity as burden or benefit? Youth, historical narrative, and the legacy of political conflict. Human Development, 53, 173-201. https://doi.org/10.1159/000320045

Hewstone, M. (2015). Consequences of diversity for social cohesion and prejudice: The missing dimension of intergroup contact. Journal of Social Issues, 71, 417-438. https://doi.org/10.1111/ josi. 12120

Hogg, M. A. (2016). Social identity theory. In S. McKeown, R. Haji, \& N. Ferguson (Eds.), Understanding peace and conflict through social identity theory (pp. 3-19). Cham, Switzerland: Springer Publishing.

Juang, L. P., Moffitt, U., ... Whitborne, S. K. (2016). Cognitive reappraisal and expressive suppression: Links to racial-ethnic discrimination and adjustment among Latino/a and Asianheritage college students. Journal of Adolescence, 53, 21-33. https://doi.org/10.1016/j. adolescence.2016.08.012

Luyckx, K., Schwartz, S. J., Berzonsky, M. D., Soenens, B., Vansteenkiste, M., Smits, I., \& Goossens, L. (2008). Capturing ruminative exploration: Extending the four-dimensional model of identity formation in late adolescence. Journal of Research in Personality, 42, 58-82. https:// doi.org/10.1016/j.jrp.2007.04.004

MacGinty, R., Muldoon, O. T., \& Ferguson, N. (2007). No war, no peace: Northern Ireland after the agreement. Political Psychology, 28, 1-11. https://doi.org/10.1111/j.1467-9221.2007.00548.x

Marcia, J. E. (1989). Identity and intervention. Journal of Adolescence, 12, 401-410.

Masten, A. S. (2014). Global perspectives on resilience in children and youth. Child Development, 85, 6-20. https://doi.org/10.1111/cdev.12205

McEvoy-Levy, S. (2006). Troublemakers or peacemakers? Youth and post-accord peace building. Notre Dame, IN: University of Notre Dame Press.

McLean, C. K., \& Syed, M. (2015). The field of identity development needs an identity: An introduction to the handbook of identity development. In K. C. McLean \& M. Syed (Eds.), The oxford handbook of identity development (pp. 1-10). Oxford: Oxford University Press.

McKeown, S. (2014). Perceptions of a superordinate identity in Northern Ireland. Peace and Conflict: Journal of Peace Psychology, 20, 505-515. https://doi.org/10.1037/pac0000105

McKeown, S., \& Taylor, L. K. (2017a). Intergroup contact and peacebuilding: Promoting youth civic engagement in Northern Ireland. Journal of Social and Political Psychology, 5, 415-434. https://doi.org/10.5964/jspp.v5i2.769

McKeown, S., \& Taylor, L. K. (2017b). Youth social identification and participation in sectarian and civic behaviour in Northern Ireland. Spain: European Association of Social Psychology.

Merrilees, C. E., Cairns, E., Goeke-Morey, M. C., Schermerhorn, A. C., Shirlow, P., \& Cummings, E. M. (2011). Associations between mothers' experience with the troubles in Northern Ireland 
and mothers' and children's psychological functioning: The moderating role of social identity. Journal of Community Psychology, 39, 60-75. https://doi.org/10.1002/jcop.20417

Merrilees, E. M., Cairns, E., Taylor, L. K., Shirlow, P., Goeke-Morey, M., \& Cummings, E. M. (2013). Social identity and youth aggressive and delinquent behaviors in a context of political violence. Political Psychology, 34, 695-711. https://doi.org/10.1111/pops.12030

Merrilees, C. E., Taylor, L. K., Goeke-Morey, M. C., Shirlow, P., Cummings, E., \& Cairns, E. (2014). The protective role of group identity: Sectarian antisocial behavior and adolescent emotion problems. Child Development, 85, 412-420. https://doi.org/10.1111/cdev.12125

Merrilees, C. E., Taylor, L. K., Goeke-Morey, M. C., Shirlow, P., \& Cummings, E. (2014). Youth in contexts of political violence: A developmental approach to the study of youth identity and emotional security in their communities. Peace and Conflict: Journal of Peace Psychology, 20, 26-38. https://doi.org/10.1037/a0035581

Motti-Stefanidi, F. (2015). Identity development in the context of the risk and resilience framework. In K. C. McLean \& M. Syed (Eds.), The Oxford handbook of identity development (pp. 472-489). New York: Oxford University Press.

O’Driscoll, D., Taylor, L. K., \& Dautel, J. (in press). Intergroup resource distribution among children living in segregated neighborhoods amid protracted conflict. Peace and Conflict: Journal of Peace Psychology.

Oyserman, D., \& Destin, M. (2010). Identity-based motivation: Implications for intervention. The Counseling Psychologist, 38, 1001-1043. https://doi.org/10.1177/0011000010374775

Phinney, J. S. (1991). Ethnic identity and self-esteem: A review and integration. Hispanic Journal of Behavioral Sciences, 13, 193-208. https://doi.org/10.1177/07399863910132005

Police Service of Northern Ireland (PSNI). (2017). Annual statistics of hate crimes. Available at: https://www.gov.uk/government/statistics/hate-incidents-and-crimes-in-northern-irelandperiod-ending-31-december-2016

Putnam, R. D. (2007). E Pluribus unum: Diversity and community in the twenty-first century the 2006 Johan Skytte Prize Lecture. Scandinavian Political Studies, 30, 137-174.

Reidy, C. M., Taylor, L. K., Merrilees, C. E., Ajduković, D., Čorkalo Biruški, D., \& Cummings, E. M. (2015). The political socialization of youth in a post-conflict community. International Journal of Intercultural Relations, 45, 11-23. https://doi.org/10.1016/j.ijintrel.2014.12.005

Roccas, S., \& Brewer, M. B. (2002). Social identity complexity. Personality and Social Psychology Review, 6, 88-106. https://doi.org/10.1207/S15327957PSPR0602_01

Romero, A. J., Edwards, L. M., Fryberg, S. A., \& Orduña, M. (2014). Resilience to discrimination stress across ethnic identity stages of development. Journal of Applied Social Psychology, 44, 1-11. https://doi.org/10.1111/jasp.12192

Schulz, M., \& Taylor, L. K. (in press). Evaluating supplemental samples in longitudinal research: replacement and refreshment approaches. Peace and Conflict: Journal of Peace Psychology.

Schwartz, S., Syed, M., Yip, T., Knight, G., Umaña-Taylor, A., Rivas-Drake, D., \& Lee, R. M. (2014). Methodological issues in ethnic and racial identity research with ethnic minority populations: Theoretical precision, measurement issues, and research designs. Child Development, 85, 58-76. https://doi.org/10.1111/cdev.12201

Sellers, R. M., Smith, M. A., ... Chavous, T. M. (1998). Multidimensional model of racial identity: A reconceptualization of African American racial identity. Personality and Social Psychology Review, 2, 18-39. https://doi.org/10.1207/s15327957pspr0201_2

Simon, B., Reichert, F., \& Grabow, O. (2013). When dual identity becomes a liability: Identity and political radicalism among migrants. Psychological Science, 24, 251-257. https://doi. org/10.1177/0956797612450889

Smith, T. B., \& Silva, L. (2011). Ethnic identity and personal well-being of people of color: A meta-analysis. Journal of Counseling Psychology, 58, 42-60. https://doi.org/10.1037/a0021528

Srivastava, D. (2012). The effects of ethnic identity, family conflict, and acculturation on racial discrimination and mental distress of second generation Asian Americans.. PhD Dissertation. New York: Fordham University, Graduate School of Education. 
Steinberg, L. (2007). Ergenlik (Adolescence). Ankara, Turkey: Imge Publication.

Stürmer, S., \& Snyder, M. (Eds.). (2009). The psychology of prosocial behavior: Group processes, intergroup relations, and helping. Chichester, England: Wiley Blackwell.

Taylor, L. K., Merrilees, C. E., Goeke-Morey, M. C., Shirlow, P., Cairns, E., \& Cummings, E. M. (2014). Political violence and adolescent outgroup attitudes and prosocial behaviors: Implications for positive intergroup relations. Social Development, 23, 840-859. https://doi. org/10.1111/sode. 12074

Taylor, L. K., Townsend, D., Merrilees, C. E., Goeke-Morey, M. C., Shirlow, P. \& Cummings, E. M. (2017). Adolescent civic engagement and perceived political conflict: The role of family cohesion. Youth \& Society. Online First. Doi: https://doi.org/10.1177/0044118X17697236

Taylor, L. K., \& Hanna, J. R. (2018). Altruism born of suffering among emerging adults in Northern Ireland. Journal of Aggression, Conflict and Peace Research, 10, 157-169. https:// doi.org/10.1108/JACPR-01-2017-0271

Taylor, L. K., \& McKeown, S. (2017). Youths' peacebuilding potential: Intergroup contact and civic participation amongst a post-accord generation in Northern Ireland. In K. Niven, S. Lewis, \& C. Kagan (Eds.), Making a difference with psychology (pp. 56-62). London: Richard Benjamin Trust.

Tummala-Narra, P., \& Claudius, M. (2013). Perceived discrimination and depressive symptoms among immigrant-origin adolescents. Cultural Diversity \& Ethnic Minority Psychology, 19, 257-269. https://doi.org/10.1037/a0032960

Umaña-Taylor, A. J., Kornienko, O., Bayless, S. D., \& Updegraff, K. A. (2018). A universal intervention program increases ethnic-racial identity exploration and resolution to predict adolescent psychosocial functioning one year later. Journal of Youth and Adolescence, 47, 1-15. https://doi.org/10.1007/s10964-017-0766-5

Umaña-Taylor, A. J., \& Shin, N. (2007). An examination of ethnic identity and self-esteem with diverse populations: Exploring variation by ethnicity and geography. Cultural Diversity and Ethnic Minority Psychology, 13, 178-186. https://doi.org/10.1037/1099-9809.13.2.178

Umaña-Taylor, A. J., Quintana, S. M., ... Yip, T. (2014). Ethnic and racial identity during adolescence and into young adulthood: An integrated conceptualization. Child Development, 85, 21-39. https://doi.org/10.1111/cdev.12196

Umaña-Taylor, A. J., \& Updegraff, K. A. (2007). Latino adolescents' mental health: Exploring the interrelations among discrimination, ethnic identity, cultural orientation, self-esteem, and depressive symptoms. Journal of Adolescence, 30, 549-567. https://doi.org/10.1016/j. adolescence.2006.08.002

Umaña-Taylor, A. J., Yazedjian, A., \& Bámaca-Gómez, M. (2004). Developing the ethnic identity scale using Eriksonian and social identity perspectives. International Journal of Theory and Research, 4, 9-38. https://doi.org/10.1207/S1532706XID0401_2

Vega, A. W., \& Gill, A. G. (2002). Drug use and ethnicity in early adolescence. New York: Kluwer Academic Publishers.

Virupaksha, H. G., Kumar, A., \& Nirmala, B. P. (2014). Migration and mental health: An interface. Journal of Natural Science Biology Medicine, 5(2), 233-239.

Vollhardt, J. R. (2009). Altruism born of suffering and prosocial behavior following adverse life events: A review and conceptualization. Social Justice Research, 22, 53-97. https://doi. org/10.1007/s11211-009-0088-1

Worrell, F. C. (2015). Culture as race/ethnicity. In K. T. McLean \& M. Syed (Eds.), The Oxford handbook of identity development (pp. 249-268). New York: Oxford University Press.

Yaylaci, F. G. (2015). Social communication among Turkish immigrants in Belgium. In I. Sirkeci, B. T. Seker, \& A. Caglar (Eds.), Turkish migration identity and integration (pp. 95-108). London: Transnational Press.

Zevallos, Z. (2008). 'You have to be Anglo and not look like me': Identity and belonging among young women of Turkish and Latin American backgrounds in Melbourne, Australia. Australian Geographer, 39, 21-43. https://doi.org/10.1080/00049180701877410 
Open Access This chapter is licensed under the terms of the Creative Commons Attribution 4.0 International License (http://creativecommons.org/licenses/by/4.0/), which permits use, sharing, adaptation, distribution and reproduction in any medium or format, as long as you give appropriate credit to the original author(s) and the source, provide a link to the Creative Commons license and indicate if changes were made.

The images or other third party material in this chapter are included in the chapter's Creative Commons license, unless indicated otherwise in a credit line to the material. If material is not included in the chapter's Creative Commons license and your intended use is not permitted by statutory regulation or exceeds the permitted use, you will need to obtain permission directly from the copyright holder. 